\title{
Simulation of Plastic Deformation Processes Through a Navier-Stokes Approach
}

\author{
Carlo Mapelli, Cristian Corna and Francesco E. Magni \\ Dipartimento di Meccanica - Politecnico di Milano, via La Masa 34, 20156 Milan
}

Italy

\section{Introduction}

The main issue for fulfilling a correct and reliable simulation of a plastic deformation process is the identification of strain, strain rate and stress fields. The definition of these aspects can also permit to state the heat developed by the plastic deformation, which is a ruling factor for the micro-structural evolution of the formed materials. On the other hand, in a lot of plastic deformation technologies, the only physical condition certainly known is the velocity assumed by the material on some boundaries (i.e. inlet and outlet velocity of the material during rolling, extrusion, wiredrawing etc.).

The use of Navier-Stokes' equations can appear unusual in the study of the mechanical behaviour of solid materials, but this is due to the fact that the plastic deformation phenomena are usually treated starting from the dynamic point of view and rarely starting from a kinematic point of view. On the other hand, the plastic deformation is related to the slip on some activated lattice systems, where the resolved shear stress becomes greater than the critical one needed for permitting the slip to take place; the slip velocities are related to the deformation and to its rate (through a time integration). The activation of some systems by the application of a stress field causes the transmission of the forces to the adjacent systems, which can assume a particular movement velocity. The transmission of the motion among the sliding systems is ruled by the viscosity of the transmitting mean (i.e. the bulk plastically deformed material). Actually, on the basis of its physical definition, the viscosity points out the relation between an applied shear stress and the gradient of the velocities transmitted among the layers parallel to the direction of the applied shear stress. So, when a velocity is imposed on a mass of plastically deformed metal, it can be transmitted to the adjacent regions as a function of the particular viscosity of the worked material, in a way mainly dependent on the temperature. Thus the velocity field, which characterizes the plastic deformation of the metal, can be calculated starting from the imposition of the correct kinematic boundary conditions. When the velocities are imposed on the boundary, the viscosity of the metal rules their transmission to the inner volumes of the metals. It is impressive and worth noting the analogy between the well known velocity profile of a liquid flowing on a plane and the morphology of the plastic flow deformation line observed in the immediately sub-surface layers of a metal which underwent a wear process featured by the plastic deformation. The difference in the movement entities between the liquid and the solid case is due to the different order of magnitude of the viscosity interesting the liquid phase and the solid one. 
The transmission of the boundary velocities within the material volume can be fully described through the imposition of the correct viscosity and by solving the Navier-Stokes' equations. In this approach, the flow stress becomes important in the determination of the correct viscosity, because it depends on the temperature, which is influenced on its turn by the enthalpy developed by the plastic deformation. This enthalpy is a function of the flow stress of the material during the evolution of the plastic deformation, as will be shown later. The Navier-Stokes' equations have to be coupled with a ricrystallization model, which allows the computation of the flow stress which is needed for the determination of a reliable viscosity, fundamental for the followed approach. In the implemented simulation model, an iterative strategy is adopted for coupling the flow analysis of plastic deformation with the thermal analysis. Strain and temperature distribution of the materials mutually affect each other, because the flow stress is temperature-dependent and the plastic work produces the heat which is dissipated by some of he applied deformation works. The stress field is computed by the constitutive equation which relates stresses, temperatures, strains and strain rates. The approach described in this work was first applied to the description of rolling and extrusion and was carefully validated through the comparison with experimental results.

\section{Theoretical background}

A flow model based on the Navier-Stokes' equations is applied to simulate the plastic deformation. Provided a function describing the viscosity of the extruded materials, the applied approach permits to obtain the material velocity field during the hot extrusion on the basis of easily measurable boundary conditions: the die geometry, the piston velocity and the velocity of the extruded material at the die exit. The stress field is computed by the constitutive equation which relates stresses, temperature, strain and strain rate (Tseng \& Wang, 1995) (Prasad \& Sashidara, 1997). In this study a hyperbolic sinusoidal function was adopted and its parameters were defined by systematic experimental tests. A model based on the Fourier equation in stationary conditions was used for describing the thermal evolution featuring the extruded material. The hot material was assimilated to a material featured by a specific viscosity and in the case of this study the viscosity was set to $5 * 10^{4} \mathrm{~Pa} \cdot \mathrm{s}$; this value was provided by the experimental evidences related to the observation of the plastic flow-stream lines by means of macrographic techniques (Chenot \& Wagoner, 1997) (Dixit et al., 1995) (Chin \& Steif, 1995). On the basis of these assumptions, the material behaviour was studied by the Navier-Stokes' equations. The use of this method permitted to calculate the velocity field in the material, starting from a little number of experimental data, easily taken from industrial production. In the case of hot extrusion the study can be developed on the basis of the knowledge about the three dimensional geometry of the die, the initial billet temperature (when it enters the press), the initial and final velocities of the material when it enters and goes out the die. Thus the experimental data needed to perform the simulation were constituted by a group of few elements which can be easily determined. The temperature at the entry into the press can be measured by several optical pyrometers. Provided the advancing velocity of the press, the velocity at the exit of the die can be approximated on the basis of the mass conservation rule. The realized model, set the viscosity of the extruded material and starting from the formerly measured data, calculates the velocity field without the need of difficult hypothesis about the friction, because a noslip condition was imposed on the boundary; the effect of the velocity gradient caused by 
friction was included in the study through the viscosity. Then, the velocity field has three components: $\mathrm{u}$ in $\mathrm{x}$-direction, $\mathrm{v}$ in $\mathrm{y}$-direction and $\mathrm{w}$ in $\mathrm{z}$-direction. As previously described, the material must respect three fundamental principles:

1. the mass conservation;

2. the momentum conservation;

3. the energy conservation.

The flow in the die was regarded as steady, three-dimensional and laminar and it was supposed that the density of the metal remained the same during the whole process, whereas the viscosity was considered temperature-dependent and followed an exponential law that was obtained by experimental measurements performed on the materials under analysis. The energy problem was solved separately because the density was supposed temperature-independent, so the final fundamental system of equations results:

$$
\left\{\begin{array}{l}
\frac{\partial(\rho u)}{\partial x}+\frac{\partial(\rho v)}{\partial y}+\frac{\partial(\rho w)}{\partial z}=0 \\
\frac{\partial}{\partial x}\left(\rho u u-\mu \frac{\partial u}{\partial x}\right)+\frac{\partial}{\partial y}\left(\rho v u-\mu \frac{\partial u}{\partial y}\right)+\frac{\partial}{\partial z}\left(\rho w u-\mu \frac{\partial u}{\partial z}\right)=-\frac{\partial p}{\partial x} \\
\frac{\partial}{\partial x}\left(\rho u v-\mu \frac{\partial v}{\partial x}\right)+\frac{\partial}{\partial y}\left(\rho v v-\mu \frac{\partial v}{\partial y}\right)+\frac{\partial}{\partial z}\left(\rho w v-\mu \frac{\partial v}{\partial z}\right)=-\frac{\partial p}{\partial y}-\rho g \\
\frac{\partial}{\partial x}\left(\rho u w-\mu \frac{\partial w}{\partial x}\right)+\frac{\partial}{\partial y}\left(\rho v w-\mu \frac{\partial w}{\partial y}\right)+\frac{\partial}{\partial z}\left(\rho w w-\mu \frac{\partial w}{\partial z}\right)=-\frac{\partial p}{\partial z}
\end{array}\right.
$$

The velocities on the boundary were imposed on the basis of experimental data. On the first section $\mathrm{w}$ was set to be equal to the advancing velocity of the press while on the last section the speed assumed the value measured at the exit of the die. On the boundary side of each section $\mathrm{u}, \mathrm{v}$ and $\mathrm{w}$ values were set to zero, imposing a no-slip condition. An iterative procedure was applied until the convergence was reached.

The determination of the velocity field allowed the strain rate $\dot{\varepsilon}_{\mathrm{ij}}$ evaluation (Patankar, 1980).

$$
\dot{\varepsilon}=\frac{1}{2}\left(\frac{\partial v_{i}}{\partial x_{j}}+\frac{\partial v_{j}}{\partial x_{i}}\right)
$$

(where $x_{i}$ and $x_{j}$ are two directions in the space and $v_{i}$ and $v_{j}$ are two components of the velocity) from which the effective strain rate $\dot{\varepsilon}$ was calculated:

$$
\dot{\varepsilon}=\sqrt{\frac{2}{3}\left[\left(\dot{\varepsilon}_{\mathrm{xx}}^{2}+\dot{\varepsilon}_{\mathrm{yy}}^{2}+\dot{\varepsilon}_{\mathrm{zz}}^{2}\right)+2\left(\dot{\varepsilon}_{\mathrm{xy}}^{2}+\dot{\varepsilon}_{\mathrm{yz}}^{2}+\dot{\varepsilon}_{\mathrm{xz}}^{2}\right)\right]}
$$

The components of the effective stress $\sigma$ (necessary for a correct thermal analysis) have been identified through: 


$$
\begin{gathered}
\sigma_{i i}=2 \eta\left(\frac{\partial v_{i}}{\partial x_{i}}\right)+p \\
\sigma_{\mathrm{ij}}=\eta\left(\frac{\partial \mathrm{v}_{\mathrm{i}}}{\partial \mathrm{x}_{\mathrm{j}}}+\frac{\partial \mathrm{v}_{\mathrm{j}}}{\partial \mathrm{x}_{\mathrm{i}}}\right)
\end{gathered}
$$

but in another approach they can be estimated using a hyperbolic sine constitutive equation suitable for high temperatures:

$$
\dot{\varepsilon}=\mathrm{A}[\sinh (\alpha \sigma)]^{\mathrm{n}} \exp (-\mathrm{Q} / \mathrm{RT})
$$

where A depends on $\varepsilon$ in a polynomial way. For each studied material, the values of parameters $\alpha, Q$ and $n$ and the expression of $A$ were determined by averaging the results of different tensile tests.

The material during the process is subjected to three different heat transfer mechanisms: conduction, convection and radiation but conduction is the main heat transfer process in the die. The Fourier equation was expressed taking into account velocities and a source term linked to the plastic deformation of the material (Patankar, 1980)(Mapelli \& Venturini, 2004)(Li et al., 2002):

$$
\mathrm{q}=\beta \cdot \frac{1}{2} \sigma_{\mathrm{ijk}} \cdot \dot{\varepsilon}_{\mathrm{ijk}}
$$

The parameter $\beta$ represents the fraction of plastic deformation power dissipated as heat and has been set to 0.9. The strain rate distribution and the heat power generated by deformation are those obtained by the module previously described. The correct computation of this term was fundamental for the correct comprehension of the microstructural phenomena occurring in the extruded alloy. On the other hand, the thermal situation of the material within the die is related to the balance between the heat development and the heat transmission through the die during the motion of the plate against the billet. Thus, a correct approach needs the performing of a time-variant simulation including the geometry variations in the extrusion system and the related movement of the die, which produces the deformation and the related heat development.

\section{Significant Application Trials}

\subsection{Hot Extrusion of Metal Alloys}

A three dimensional space was studied considering three Cartesian coordinates: $z$-axis was in the extrusion direction; $x$-axis was the horizontal direction perpendicular to z-axis while $\mathrm{y}$-axis was the vertical direction perpendicular to z-axis. Actually the studied geometry (Figure 1, Figure 2) dis not permit the simplification through the 2D-axisymmetric simulation, because this could be reliable only in the presence of one central hole of extrusion. 




Figure 1. The studied geometry typical of an inverse extrusion



Figure 2. The studied geometry typical of an inverse extrusion and the applied reference system

The simulations were performed setting two different initial thermal conditions $\left(650^{\circ} \mathrm{C}\right.$ and $\left.750^{\circ} \mathrm{C}\right)$ of the brass CW617N. The die movement against the billet $(0.15 \mathrm{~m} / \mathrm{s})$ was imposed using a module which modifies the geometry of the mesh following the time-variant displacement of the die. Even in this transient condition the model remained very stable, but this was probably due to the fact that working in presence of the high viscosity, typical of the solid material, prevents any turbolent phenomena. The condition of $p=0$ was imposed on the two exit sections, for leading the material towards the correct position of the die play. The velocity field within the die appears to be extremely plausible (Figure 3, Figure 4, Figure $5)$. 




Figure 3. The vertical component of the velocity field developed during the inverse extrusion of the brass billet, visualized along a plane including the extrusion die

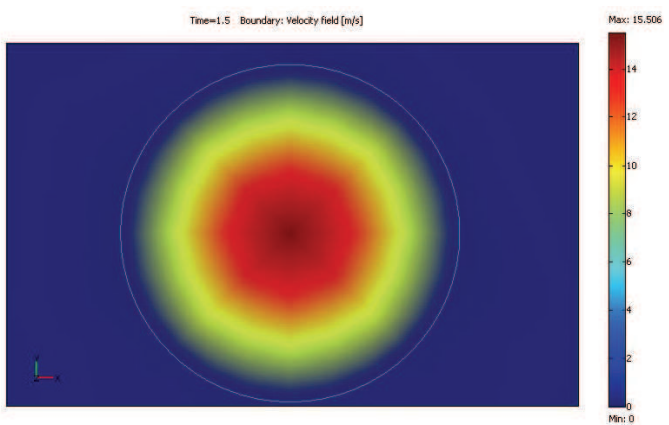

Figure 4 . The values assumed by the vertical component of the velocity field developed within the extrusion die during the deformation of the brass billet

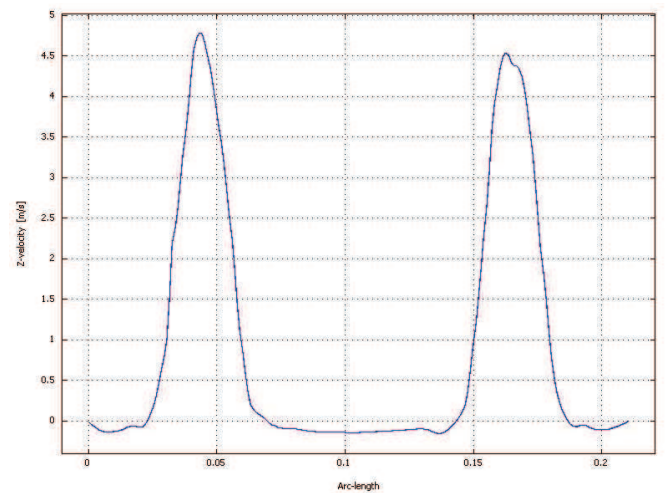

Figure 5. Trend of the vertical component of the velocity field just under the extrusion die holes

The associated stress field is reliable and its computation allowed to perform a correct identification of the thermal source and of the thermal state realized within the extruded brass (Figure 6, Figure 7, Figure 8, Figure 9). 


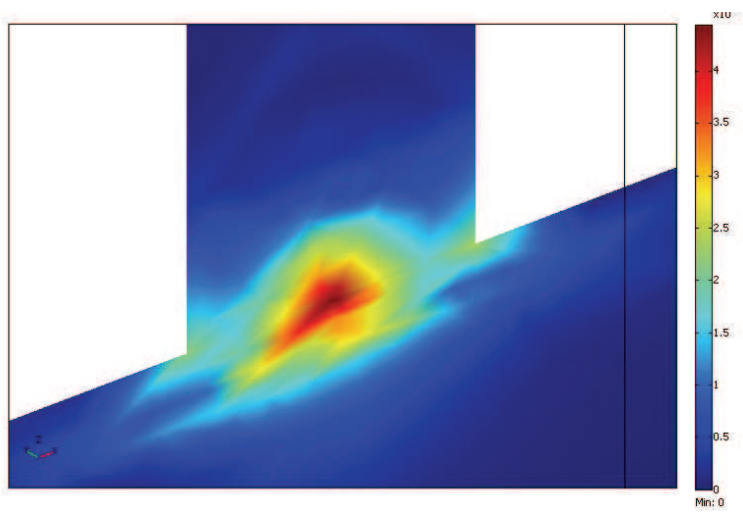

Figure 6. Stress field developed in one hole of the extrusion die

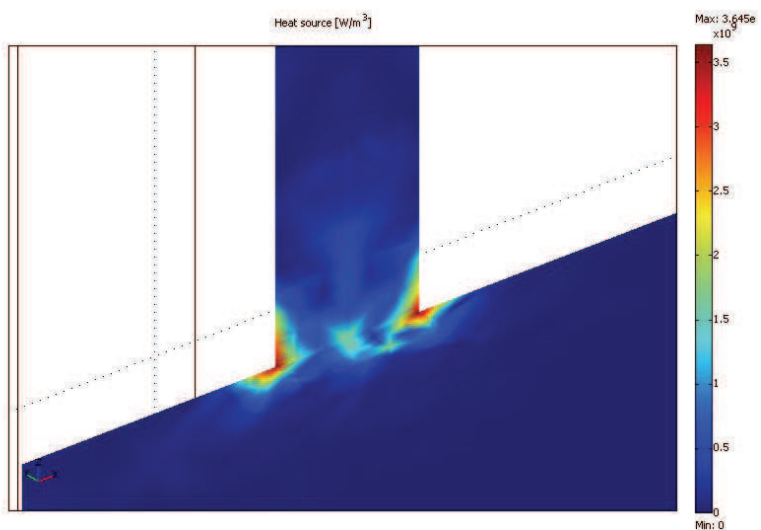

Figure 7. Heat power developed in one hole of the extrusion die

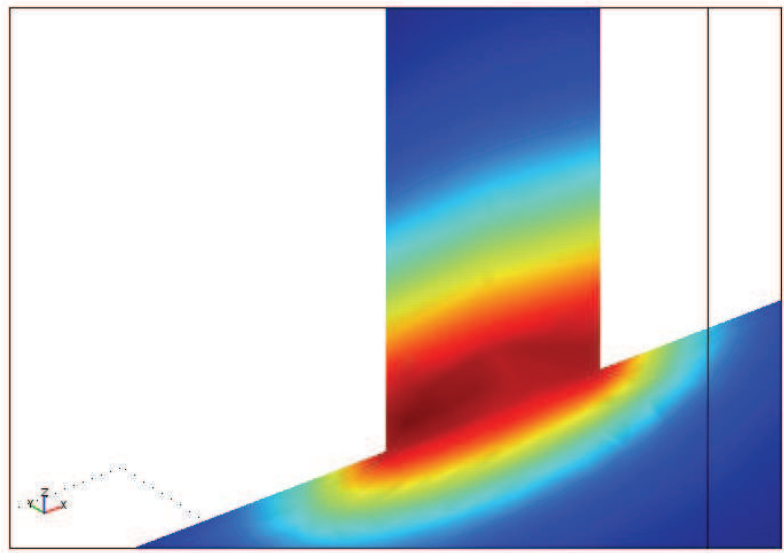

Figure 8. Qualitative image of the thermal state developed in one hole of the extrusion die 


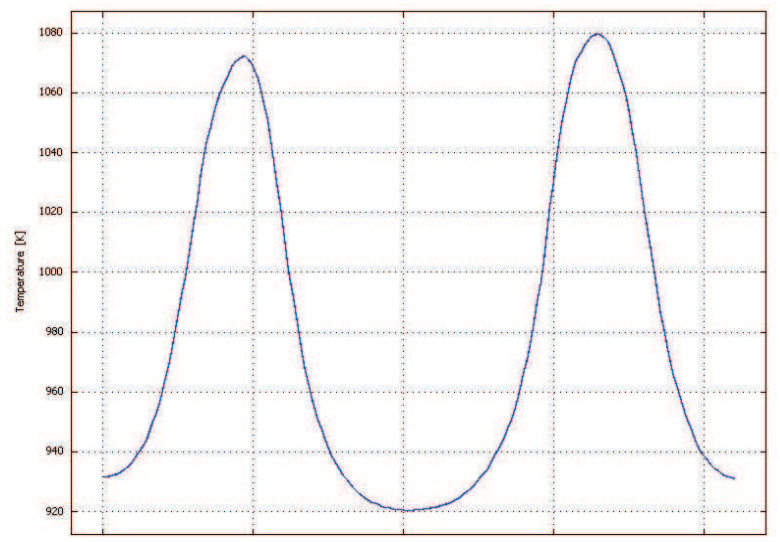

Figure 9. Profile of the temperature developed in the holes of the extrusion die

The validation was performed through the comparison between the hardness experimental data and the computed temperature value (Figure 10). The higher is the imposed thermal state, the lower is the measured final hardness and this is completely consistent with the well known effect of the induced thermal state on the softening phenomena effecting the extruded material.

The effect of temperature trend revealed along the section of the extruded material was also pointed out.

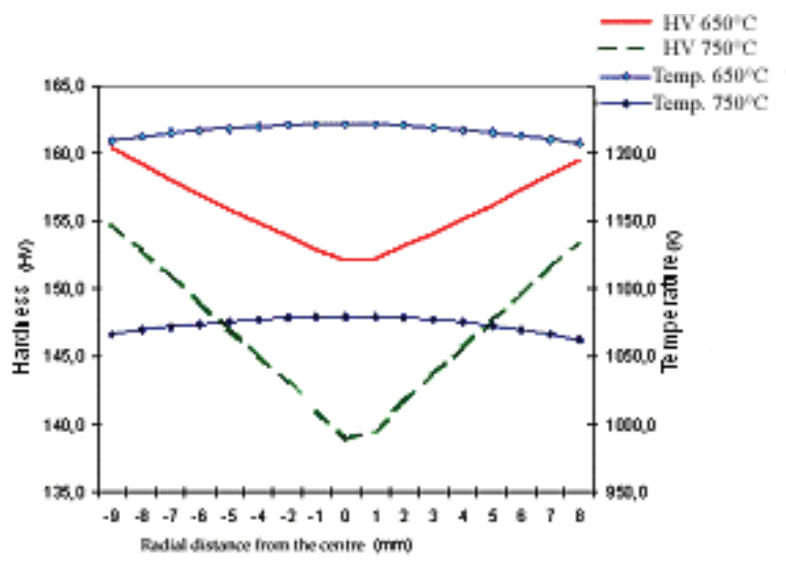

Figure 10. Comparison between the measured hardness profile in the extruded products and the temperature developed in the extrusion die

\subsection{Steel Rolling}

The rolling of metal alloys represents another example of the application of a Navier-Stokes approach for a reliable description of the plastic deformation process on the basis of boundary conditions which can be defined with a good certainty level.

In this case the boundary conditions to be defined are:

- the inlet velocity of the metal alloy between the strand rollers; 
- $\quad$ the outlet velocity;

- $\quad$ the working rollers peripheric velocity.

Once the inlet velocity of the forwarding material is known, the outlet velocity can be easily stated through the mass conservation. For instance, in the case of a rectangular section:

$$
\mathrm{v}_{\text {out }}=\frac{\mathrm{v}_{\text {in }} \mathrm{h}_{\text {in }}}{\mathrm{h}_{\text {out }}}
$$

while the velocity of the surface in contact with the working rollers can be stated equal to the roller one. This statement is not precisely correct, because it is well known that the peripheral velocity of the rollers is equal to the one of the rolled products only at the neutral point or in the so called neutral area. This inconsistency can be rapidly overlapped drawing a thin layer of metal over the rolled products and imposing on this side the velocity of the rollers, so on the basis of the imposed viscosity and of the inlet and outlet velocities the system computes the correct velocity profile on the surface of the rolled material.

The computed field of stress, strain and strain rate is completely consistent with the one turned out through other approaches (Figure 11).

Moreover, the advantage of the shown approach consists in the fact that this allows a rapid and reliable simulation of some innovative rolling techniques, like the asymmetric simulation, in which the velocity of the upper and lower rollers are different. In this case the approach based on the Navier-Stokes formulation is suitable without any problem avoiding the imposition of strange and unusual condition on the friction interesting the contact among the rollers and the material going to be thinned. The comparison between the shear stress profile in a traditional rolling operation and the asymmetric one along the middle line between the entry and the exit sections can be clearly pointed out through a very simple change of the peripheral imposed velocity (Figure 12). Thus, also in this innovative and unusual situation, the developed approach seems to show its good performance.



m

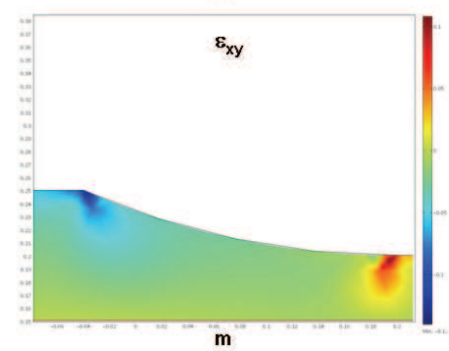



m

Figure 11. Example of deformation patterns computed for a rolling operation 


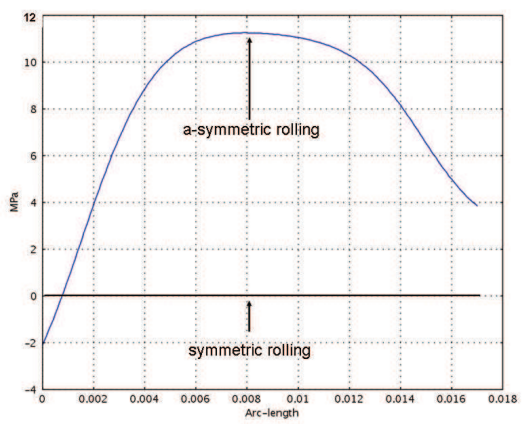

Figure 12. Comparison of the shear stresses revealed at the middle of the thickness of rolled steel in a-symmetric and symmetric rolling conditions

\section{Conclusions}

The use of the Incompressible Navier-Stokes equations for defining the velocity and the stress fields and the heat power source within the die appears to be an efficient method, also because the high viscosity of the solid material to be deformed avoids the treatment of the turbulent behaviour. The other advantage is represented by the few and easily measurable variables that must be taken into account in order to perform the simulations.

The future development can be focused on the application of the shown approach to more complex geometrical situation.

\section{References}

Chenot J.L., Wagoner, R.H. (1997). Fundamentals of metal forming, pp.369-371, John Wiley \& Sons, ISBN-9780471570042, United Kingdom.

Chin, R.K.; Steif, P.S. (1995). A computational study of strain inhomogeneity in wiredrawing, Int.J.Mach.Tools Manufact., 35, 8, 1995, pp. 1087-1098, ISSN 0890-6955.

Dixit, P.M.; Lal, G.K.; Venkata Reddy, N.(1995). Die design for axisymmetric extrusion, Journal of Materials Processing Technology, 55, 1995, pp.331-339, ISSN 0924-0136.

Li, L.X.; Rao, K.P.; Lou, Y.; Peng, D.S. (2002), A study on hot extrusion of Ti-6Al-4Vusing simulations and experiments, International Journal of Mechanical Sciences, 44, 12, 2002, pp. 2415 -2425, ISSN 0020-7403.

Mapelli, C.; Venturini, R. (2004). Flow, thermal and microstructural analysis during the cast rolling of steel in In-line Strip Production process, Steel Research Int., 75, 4, 2004, pp. 257-266, ISSN 1611-3683.

Patankar, S.V. (1980). Numerical heat transfer and fluid flow, pp1-197, McGraw-Hill, ISBN 0070487405.

Prasad, Y.V.R.K; Sasidhara, S. (1997). Hot working guide: a compendium of processing maps, pp.1-23, ASM international, ISBN-100871705982, Materials Park - Ohio (USA).

Tseng, A.A.; Wang, S.R. (1995). Macro- and micro-modeling of hot rolling of steel coupled by micro-costitutive relation, Material \& Design, 16, p. 315-336, ISSN 0261-3069. 


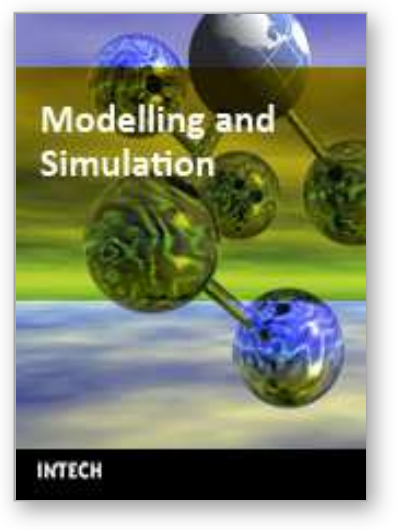

\author{
Modelling and Simulation \\ Edited by Giuseppe Petrone and Giuliano Cammarata
}

ISBN 978-3-902613-25-7

Hard cover, 688 pages

Publisher I-Tech Education and Publishing

Published online 01, June, 2008

Published in print edition June, 2008

This book collects original and innovative research studies concerning modeling and simulation of physical systems in a very wide range of applications, encompassing micro-electro-mechanical systems, measurement instrumentations, catalytic reactors, biomechanical applications, biological and chemical sensors, magnetosensitive materials, silicon photonic devices, electronic devices, optical fibers, electro-microfluidic systems, composite materials, fuel cells, indoor air-conditioning systems, active magnetic levitation systems and more. Some of the most recent numerical techniques, as well as some of the software among the most accurate and sophisticated in treating complex systems, are applied in order to exhaustively contribute in knowledge advances.

\title{
How to reference
}

In order to correctly reference this scholarly work, feel free to copy and paste the following:

Carlo Mapelli, Cristian Corna and Francesco E. Magni (2008). Simulation of Plastic Deformation Processes Through a Navier-Stokes Approach, Modelling and Simulation, Giuseppe Petrone and Giuliano Cammarata (Ed.), ISBN: 978-3-902613-25-7, InTech, Available from:

http://www.intechopen.com/books/modelling_and_simulation/simulation_of_plastic_deformation_processes_thr ough_a_navier-stokes_approach

\section{INTECH}

open science | open minds

\author{
InTech Europe \\ University Campus STeP Ri \\ Slavka Krautzeka 83/A \\ 51000 Rijeka, Croatia \\ Phone: +385 (51) 770447 \\ Fax: +385 (51) 686166 \\ www.intechopen.com
}

\author{
InTech China \\ Unit 405, Office Block, Hotel Equatorial Shanghai \\ No.65, Yan An Road (West), Shanghai, 200040, China \\ 中国上海市延安西路65号上海国际贵都大饭店办公楼405单元 \\ Phone: +86-21-62489820 \\ Fax: +86-21-62489821
}


(C) 2008 The Author(s). Licensee IntechOpen. This chapter is distributed under the terms of the Creative Commons Attribution-NonCommercialShareAlike-3.0 License, which permits use, distribution and reproduction for non-commercial purposes, provided the original is properly cited and derivative works building on this content are distributed under the same license. 